\title{
AN EXAMINATION OF MEASURING AND CONTROL SYSTEMS IN AN INDUSTRIAL BIOGAS PLANT IN TURKEY
}

\author{
Mehmet Keskin Kilic ${ }^{1}$, Nurettin Abut ${ }^{2}$, Fatma Canka Kilic ${ }^{1, *}$, Muharrem Eyidoğan ${ }^{3}$, Durmus Kaya ${ }^{3}$ \\ ${ }^{I}$ Department of Electrical and Energy, Kocaeli Vocational School, Kocaeli University, Kullar Beldesi, Mahmutpaşa \\ Cad. No: 1, PK: 41140 Kullar/Başiskele/Kocaeli, Turkey; \\ ${ }^{2}$ Department of Electrical Engineering, Faculty of Engineering, Kocaeli University, 41380 Umuttepe, Kocaeli, \\ Turkey; \\ ${ }^{3}$ Department of Energy Systems Engineering, Faculty of Technology, Kocaeli University, 41380 Umuttepe, Kocaeli, \\ Turkey;
}

*Corresponding author Fatma Canka Kilic, e-mail: fatmacanka@ hotmail.com; Received June, 2018; Accepted July, 2018; Published January, 2019;

DOI: https://doi.org/10.31407/ijees9102

\begin{abstract}
As an alternative method to the classical energy productions, the concept that energy can be consumed where it is produced has been successfully applied today to minimize the increasing energy costs and use more efficient and clean energy. Even though the fossil-based energy sources are gradually decreasing, they continue to harm the environment with many negative effects such as air, water, soil pollution and global warming. Protecting the environment from these harms, and reducing these negative effects has become the most important targets of many countries in the world. The solutions can be found via renewable energy sources by producing "green power". As these types of solutions increase, the ratio of greenhouse gas emitted at the atmosphere decreases, which is an extremely environmentally friendly approach. Despite the possibility that fossil fuels will end up in a certain period, these alternative energy productions need to be spread over a wider area to achieve sustainable green energy productions. As a good alternative choice, biogas production by evaluating organic wastes in an industrial biogas plant, methane gas is produced and converted into heat and electricity energy in cogeneration systems. Measurement and control systems are needed for the biogas production and cogeneration systems. In this context, pressure, level, temperature measurements are made and biogas content is analyzed, successfully. The pump, mixer, blower and heating system are controlled according to the information obtained from the measuring systems. In this study, an examination of measuring and control systems in an industrial biogas plant in Turkey is discussed in detail.
\end{abstract}

Key words: Industrial Biogas Plant, Measuring and Control System, Sensor 